\title{
DEBATES
}

\section{Mulheres nos partidos politicos brasileiros: uma análise de estatutos partidários e sítios eletrônicos}

\author{
Brazilian political parties' women's sections: an analysis of websites
}

\section{Daniela Rezende \\ Rayza Sarmento \\ Louise Tavares}

\section{Resumo}

Este artigo apresenta uma análise sobre os órgãos de mulheres dos partidos políticos brasileiros, considerando os estatutos e os sítios eletrônicos dos partidos políticos com representação na Câmara dos Deputados brasileira na 54a legislatura (2011-2015), a fim de entender as formas como os órgãos de mulheres aparecem em duas arenas importantes na construção dos partidos: suas diretrizes estatutárias e sua apresentação pública oficial na internet. $\mathrm{O}$ conjunto das análises realizadas indica que os órgãos de mulheres têm atuação limitada, o que aponta para seu caráter predominantemente retórico. Ainda que voltada à análise específica de órgãos partidários, a pesquisa realizada pode contribuir para elucidar questóes mais amplas, relacionadas a atividades partidárias fundamentais, como o recrutamento de militantes e lideranças e a mobilização política.

\section{Palavras-chave}

Partidos Políticos; Órgãos de Mulheres; Estatutos; Internet.

\begin{abstract}
This article presents an analysis of women's sections in Brazilian political parties, considering the statutes and websites of political parties represented in the Brazilian House of Representatives in the 54th legislature (2011-2015) in order to understand the ways in which the bodies of women appear in two important arenas in the construction of the parties, namely, their statutory guidelines and their official public presentation on the internet. The set of analyses carried out indicates that women's sections have limited performance, which points to their predominantly rhetorical character. Although focused on the specific analysis of party structures, the research carried out can contribute to elucidating broader issues related to fundamental party activities, such as the recruitment of militants and leaders and political mobilization.
\end{abstract}

\section{Keywords}

Political Parties; Women's Sections; Statutes; Internet. 
44 | Daniela Rezende, Rayza Sarmento e Louise Tavares

\section{Introdução ${ }^{1}$}

Este trabalho apresenta uma análise descritiva sobre os órgãos de mulheres dos partidos políticos brasileiros e sua relação com a representação política feminina. Tais órgáos podem atuar de forma a promover equidade de gênero, monitorando os compromissos partidários relativos a esse princípio, além de funcionarem como órgão consultivo e formativo. Também podem incentivar a organização e mobilização das filiadas, tendo como referência a igualdade de oportunidades e direitos. Entretanto, sua capacidade operacional e relevância política dependem de suas prerrogativas e funçôes na organização partidária e de suas estratégias de coordenação e mobilização (SACHETT, 2005 e 2009 apud ROZA, LLANOS e GARZÓN DE LA ROZA, 2010). Apesar de sua importância, as análises sobre essas organizaçóes são escassas, o que pode estar relacionado ao grande número de partidos políticos existentes no Brasil e à dificuldade em acessar dados relacionados à sua organização interna (RIBEIRO, 2013).

De forma a contribuir para superar essa lacuna, a análise se debruçou nos estatutos e nos sítios eletrônicos dos partidos políticos com representação na Câmara dos Deputados brasileira na 54 legislatura (2011-2015). O objetivo da análise foi avaliar as formas como os órgáos de mulheres aparecem em duas importantes dimensôes partidárias, quais sejam, suas diretrizes estatutárias e sua apresentação pública oficial na internet. A hipótese que orientou a investigação de baseou em trabalho seminal de Lovenduski (1993) e prevê que as organizaçôes partidárias de mulheres no Brasil se configuram como ações afirmativas voltadas ao incremento da representação política de mulheres. A fim de verificar se a hipótese aventada se sustenta, o desenho empírico da investigação possui caráter documental e se desenvolveu em duas etapas. A primeira se concentrou na análise dos estatutos partidários $^{2}$, com o fim de avaliar as iniciativas adotadas pelos partidos em tais documentos no sentido de garantir maior inclusão de mulheres. A segunda etapa se voltou à análise dos sítios eletrônicos dos órgãos partidários de mulheres, para entender como tais ferramentas poderiam fomentar processos de interação e informação proporcionados pela dimensão on-line, além de coletar mais informaçóes relativas às instâncias de mulheres, relacionadas ao seu funcionamento e organização.

\footnotetext{
${ }^{1}$ As autoras agradecem a FAPEMIG pelo auxílio que possibilitou a realização da pesquisa.

${ }^{2}$ DEM (2008), PCdoB (2001), PDT (1999), PHS/PODE (2009), PMN (2008), PP (2009), Cidadania (2009), PR/PL (2009), Republicanos (2008), Patriota (2008), PRTB (2004), PSB (2008), PSC (2007), PSDB (2007), PSL (2004), PSOL (2004), PT (2007), Avante (1996), PTB (2009), PTC (2008), PV (2009).
} 
Para tanto, o artigo está dividido em duas partes além desta breve introdução. $\mathrm{Na}$ primeira, discutimos a literatura preocupada com a inserção feminina nos partidos; em seguida, apresentamos os dados referentes às análises empíricas, ressaltando a importância de tomar os estatutos e os sites como fontes de dados. Finalmente, apresentamos as consideraçôes finais, que indicam que os órgãos de mulheres têm atuação limitada, o que aponta para seu caráter predominantemente retórico.

\section{Mulheres, representação e partidos politicos}

A análise dos órgãos de mulheres nos partidos parte de um cenário nacional alarmante de sub-representação feminina. Os dados históricos mostram que o percentual de eleitas para a Câmara dos Deputados permanece inferior a 10\% desde a década de 1940. Tal cenário se manteve quase inalterado muito embora iniciativas sancionadas em forma de leis - como a Lei $n^{\circ} 9.100 / 1995$, a $n^{\circ} 9.504 / 1997$, a $\mathrm{n}^{\circ}$ $12.034 / 2009$ e a Lei no $13.165 / 2015$ - tenham contribuído para a implementaçáo de cotas de gênero nas listas eleitorais, assim como convergiram em direção à obrigatoriedade de que os partidos destinem parte de seus recursos ao fomento da participação política de mulheres, entre outras estratégias.

Essas conquistas, apesar de necessárias, não têm se mostrado suficientes, visto que o país se encontra na $143^{a}$ posição, em um total de 188 posições, no ranking de mulheres em legislativos nacionais da InterParliamentary Union (IPU). Todavia, tais normativas explicitam a centralidade dos partidos políticos no tocante à eleiçáo de mulheres no Brasil, uma vez que, tal como exposto por Monzoy (2011), tais organizaçóes representam a principal via de acesso a cargos de representaçáo ao funcionarem como gatekeepers, uma vez que são os responsáveis pelo processo de recrutamento político (NORRIS, 2013) no país. Além disso, não se pode negligenciar o fato de que os partidos atuam como mediadores na distribuição de recursos eleitorais no Brasil (ARAÚJO, 2005; ÁLVARES, 2008; SACCHET e SPECK, 2012).

A investigação tomou os partidos políticos como unidade de análise. Mais ainda, concebe que essas são organizaçôes generificadas, é dizer, a dimensão de gênero constitui um eixo de hierarquização e desigualdade no interior das estruturas partidárias (LOVENDUSKI, 1993; CAUL, 1997, 1999, 2001, 2011 e 2013; O'BRIEN, 2012 e 2015; ARAÚJO, 2005; BARREIRA e GONÇALVES, 2012; SANTOS, PAULA e SEABRA, 2012; ROZA, LLANOS e GARZÓN DE LA ROZA, 2010; MONZOY, 2011, REZENDE, 2019). Como afirma Caul (2013, loc.12343), "[...] apesar de não haver regras formais que impeçam a presença de mulheres nos 
partidos das democracias contemporâneas, suas oportunidades nos partidos são relativamente mais restritas que as dos seus colegas do sexo masculino" (traduçáo nossa).

Além disso, merece destaque o posicionamento de Lijphart (2003 apud SACCHET, 2011), que pode ser inserido no rol de pesquisadores que defendem a relevância de se considerar o grau de inclusão política das mulheres como um indicativo da qualidade da democracia. Isso porque, segundo ele, avaliar a representação política das mulheres é uma forma de analisar como se dá a representação de grupos minoritários nas democracias e, consequentemente, do grau de desenvolvimento de seus direitos. Portanto, “[...] compreender a condiçáo de inclusão ou exclusão sociopolítica das mulheres é um bom meio para avaliar níveis de desigualdade entre diferentes grupos sociais" (SACCHET, 2011, p. 161).

Em igual importância, destaca Monzoy (2011), a maior inserção de mulheres na arena política institucional equivale a uma maneira de melhorar a qualidade do sistema democrático, tendo em vista o esperado impacto positivo no que se refere à legitimidade das instituiçôes representativas. Vale ressaltar, em decorrência disso, que a potencialidade de que dispóem os partidos políticos de desempenhar o papel de propulsores da inclusão de mais mulheres na política em direção à equidade de gênero consiste na espinha dorsal deste estudo, uma vez que os partidos representam a principal via de acesso a cargos de representação nas democracias analisadas (MONZOY, 2011). Dessa forma, entendemos que as elites partidárias detêm singular importância ao desempenharem papel crucial no que tange a quaisquer esforços destinados ao incremento da participação de mulheres na política.

\section{Desenho da pesquisa e análise dos dados}

Para a compreensão dos órgáos de mulheres, foram analisados apenas os partidos políticos com representação na Câmara dos Deputados brasileira na $54^{a}$ legislatura (2011-2015), quais sejam: PT, DEM, PSC, $\mathrm{PTdoB}^{3}, \mathrm{PPS}^{4}, \mathrm{PMDB}^{5}, \mathrm{PRB}^{6}, \mathrm{PR}, \mathrm{PDT}$, PCdoB, PTC, PSDB, PV, PRTB, PMN, PSB, PSL, PP, PHS 7 , PSOL, PRP ${ }^{8}$ e PTB.

Uma primeira etapa da pesquisa se concentrou na análise documental dos

\footnotetext{
${ }^{3}$ Atualmente AVANTE.

${ }^{4}$ Atual Cidadania.

${ }^{5}$ Renomeado de MDB.

${ }^{6}$ Atualmente Republicanos.

${ }^{7}$ Atual PODEMOS.

${ }^{8}$ Atualmente PATRIOTA.
} 
estatutos partidários disponíveis no site do Tribunal Superior Eleitoral, aprovados até o dia 03 de abril de 2010, prazo limite para que as novas disposiçóes estatutárias incidissem sobre o recrutamento eleitoral realizado pelos partidos com vistas a disputar o pleito desse mesmo ano, ocorrido em outubro. O recorte temporal se justifica pela expectativa de que as atividades online e offline dos órgãos de mulheres fossem mais intensas em anos eleitorais, dados os objetivos de tais órgãos apontados pela literatura, qual seja, o recrutamento de lideranças femininas e potenciais candidatas aos peitos eleitorais.

Nesse sentido, cabe observar que, dentre os 22 partidos que compuseram a amostra da pesquisa, apenas 14 elegeram pelo menos uma mulher nas eleiçóes para a Câmara dos Deputados em 2010, o que significa que oito partidos não elegeram nenhuma deputada federal. São eles: PHS, PPS, PRB, PRTB, PSL, PSOL, PTC e PRP.

As informações sobre os estatutos incluídos na análise são detalhadas na Tabela 1.

Tabela 1 - Partidos incluídos na amostra, segundo data da convenção partidária e data de publicação dos estatutos no site do TSE

\begin{tabular}{l|c}
\hline \multicolumn{1}{c|}{ Partido } & Data publicaçáo TSE \\
\hline DEM & $24 / 09 / 2008$ \\
\hline PCdoB & $21 / 07 / 2006$ \\
\hline PDT & $03 / 05 / 2000$ \\
\hline PHS & $10 / 03 / 2010$ \\
\hline PMDB & $05 / 10 / 2009$ \\
\hline PMN & $04 / 08 / 2009$ \\
\hline PP & $01 / 10 / 2009$ \\
\hline PPS & $11 / 12 / 2009$ \\
\hline PR & $13 / 08 / 2009$ \\
\hline PRB & $21 / 09 / 2009$ \\
\hline PRP & $07 / 08 / 2008$ \\
\hline PRTB & $05 / 07 / 2004$ \\
\hline PSB & $21 / 09 / 2009$ \\
\hline PSC & $17 / 12 / 2007$ \\
\hline PSDB & $16 / 06 / 2008$ \\
\hline PSL & $20 / 06 / 2006$ \\
\hline PSOL & $30 / 09 / 2005$ \\
\hline PT & $04 / 07 / 2008$ \\
\hline PT do B & $14 / 08 / 1996$ \\
\hline
\end{tabular}


48 | Daniela Rezende, Rayza Sarmento e Louise Tavares

\begin{tabular}{l|l}
\hline PTB & $04 / 08 / 2009$ \\
\hline PTC & $06 / 08 / 2008$ \\
\hline PV & $05 / 10 / 2009$ \\
\hline
\end{tabular}

Fonte: Elaborado pelas autoras a partir de dados do TSE.

Um segundo movimento foi a análise dos sites dos partidos políticos e dos órgãos de mulheres nesses partidos em nível nacional. Ainda há poucos estudos comparativos sobre os sites dos partidos políticos brasileiros (ROCHA, 2014; BARREIRA e GONÇALVES, 2012; BRAGA, ROCHA e CARLOMAGNO, 2015), e nesses existentes não há uma preocupação sistemática com a dimensão de gênero e nem com possíveis estratégias partidárias relacionadas ao recrutamento de potenciais candidatas. A Tabela 2 detalha a amostra considerada na pesquisa:

Tabela 2 - Amostra incluída na análise de sítios eletrônicos de órgãos de mulheres dos partidos políticos brasileiros, 2010

\begin{tabular}{c|l}
\hline Partido & Endereço eletrônico dos órgáos de mulheres \\
\hline DEM & https://web.archive.org/web/20100326031946/http://www.mulherdemocrata.org.br/ \\
\hline PCdoB & https://web.archive.org/web/20101006163436/http://www.pcdob.org.br/secretarias/secretaria-mulheres/ \\
\hline PMN & https://web.archive.org/web/20101006044120/http://www.pmnmulher.org.br/ \\
\hline PSDB & https://web.archive.org/web/20100912233621/http://www.psdb.org.br/index.php/em-acao/psdb-mulher \\
\hline PDT & https://web.archive.org/web/20100308035253/http://pdt12.locaweb.com.br/paginasmenu.asp?id=18 \\
\hline PMDB & https://web.archive.org/web/20101019161026/http://www.pmdb.org.br/pmdbmulher.php \\
\hline PT & https://web.archive.org/web/20100402122803/http://www.pt.org.br/portalpt/secretarias/mulheres-16.html \\
\hline PPS & https://web.archive.org/web/20100727152934/http://mulheres.pps.org.br/ \\
\hline PP & https://web.archive.org/web/20100620191430/http://www.ppmulher.org.br/site/ \\
\hline PRTB & https://web.archive.org/web/20101006012906/http://www.prtb.org.br/prtb_mulher.html \\
\hline PRB & https://web.archive.org/web/20100515182626/http://www.prb.org.br/ \\
\hline PSB & https://web.archive.org/web/20091124094429/http://www.psbnacional.org.br/index.php/content/view/118.html \\
\hline PTB & https://web.archive.org/web/20100808051202/http://www.ptb.org.br:80/?estado=mu \\
\hline PV & https://web.archive.org/web/20100728090455/http://www.pvmulher.org.br/ \\
\hline FOnte: Elaborado
\end{tabular}

Fonte: Elaborado pelas autoras.

A seguir, discutimos em detalhe as escolhas metodológicas realizadas e apresentamos os resultados das análises desenvolvidas.

\section{Análise dos estatutos partidários}

Para a análise dos estatutos partidários, tomamos como referência os estudos de Lovenduski (1993), para quem há duas formas de se caracterizar as mudanças perpetradas pelos partidos políticos: programáticas ou organizacionais. Mudanças programáticas referem-se a princípios e políticas, ao passo que alteraçôes 
organizacionais dizem respeito "[...] a métodos de recrutamento e promoção das mulheres a posiçôes estratégicas no interior dos partidos” (LOVENDUSKI, 1993). Nesse sentido, pode-se dizer que há uma hierarquia entre tais estratégias, uma vez que as últimas implicam em alteraçóes nas distribuições de recursos, enquanto as primeiras podem ter efeito apenas retórico, especialmente se se considera que, em democracias presidencialistas, os programas partidários não são vinculantes e não influenciam a atuação dos partidos ou de seus membros, tal como ocorre em democracias parlamentaristas.

Além disso, para Lovenduski (1993), as mudanças classificadas em organizacionais se subdividem em três categorias, a saber: 1) retórica: transformação que se refere à inserção das demandas das mulheres em documentos, campanhas, plataformas e discursos; 2) açôes afirmativas: que dizem respeito à previsão de treinamentos às mulheres, auxilio financeiro, creche, etc.; e 3) discriminaçáo positiva: que consiste na regulamentação de reserva de vagas para mulheres nas listas partidárias e em instâncias intrapartidárias.

Diante do exposto, circunscrevemos a investigação do conteúdo disposto nos estatutos partidários às mudanças organizacionais, uma vez que essas podem implicar transformaçóes mais substantivas que aquelas expressas pelas transformaçóes programáticas. Para isso, utilizamos o método de análise documental, tomando como fonte os estatutos partidários disponíveis no site do TSE9 (BRASIL, s/d).

Os estatutos partidários se mostram como fontes importantes para análise documental (GIL, 2007), dado que manifestam as diretrizes de atuação e, discursivamente, mostram as concepçóes de uma determinada legenda, especialmente no tangente ao nosso interesse específico - a inserção das questôes de gênero. As análises de documentos, tais como os estatutos, tornam-se relevantes, defende Gil (2007, p. 47), “[...] não porque respondem definitivamente a um problema, mas porque proporcionam melhor visão desse problema ou, entáo, hipóteses que conduzem a sua verificação por outros meios”. Trata-se de uma aproximação teoricamente sustentada em uma "fonte rica e estável de dados" (GIL, 2007, p. 46). Além disso, como aponta Ribeiro (2013, p. 229),

[...] a análise de documentos partidários se coloca como estratégia cientificamente válida para aumentar o conhecimento sobre as estruturas

\footnotetext{
${ }_{9}^{9}$ Disponível em: <http://www.tse.jus.br/partidos/partidos-politicos/registrados-no-tse>. Acesso em: 08 dez. 2020.
} 
dos partidos brasileiros. [...] Por outro lado, como faceta mais pública das legendas, os regulamentos são fundamentais em pesquisas que procuram se alicerçar sobre bases empíricas sólidas, pelo simples fato de estarem sempre disponíveis ao pesquisador. $\mathrm{O}$ fácil acesso permite, ainda, a adoção de perspectivas comparadas intra e transnacionais, e também entre diferentes momentos de um mesmo partido. Por fim, as normas formais importam porque constituem as instituiçôes que regulam a dinâmica intrapartidária, em termos da competição pelos postos dirigentes, das relações entre as instâncias, do controle sobre os recursos organizativos etc. - o que faz delas um cavalo de batalha constante nos conflitos intrapartidários. (KATZ e MAIR, 1992, p. 7-8 apud RIBEIRO, 2013, p. 229).

Desse modo, em relação às estratégias retóricas, operacionalizamos a pesquisa a fim de identificar aspectos como uso de linguagem inclusiva, mobilização das palavras "mulher" e "gênero", menção a princípio de não discriminação e à igualdade de gênero.

Os dados coletados mostram que 11 dos 22 partidos analisados adotam em alguma medida linguagem inclusiva, flexionando termos no masculino e no feminino ao longo do texto. São eles: PDT, PRP PSL, PT, PPS PC do B, PP, PSOL, PTB, PSB, PSDB. Como exemplo, indicamos abaixo alguns trechos do estatuto do PCdoB analisado, que adota linguagem inclusiva ao longo de todo o documento. Em seguida, indicamos trechos do estatuto do PDT, registrado em 1999, em que a linguagem inclusiva é adotada em alguns artigos.

Estatuto do PCdoB - Artigo 2o: O Partido Comunista do Brasil (PCdoB) é uma associaçấo livre e voluntária de cidadãos e cidadãs, maiores de 18 (dezoito) anos, no gozo de seus direitos políticos, que aceitam seu Programa e Estatuto. Artigo 40: Os filiados e filiadas são um patrimônio político do Partido, que empreende esforços permanentes para elevar sua consciência política, sua participação na vida partidária e seu compromisso militante. (PCdoB, 2001).

Estatuto do PDT - Artigo 26: O PDT, na composição de todos os seus órgãos dirigentes e nominatas de candidatos a cargos eletivos, marcará a sua preferência pela de companheiros/as com razoável tempo de filiação e provindos das classes pobres e dos excluídos, com o necessário preparo pessoal ou representação social, entre trabalhadores, agricultores, assalariados em geral, sindicalistas, profissionais, pequenos empresários, aposentados, jovens, negros e mulheres, devendo, na composição de tais órgãos e nominatas, atingir um mínimo de trinta por cento $(30 \%)$ de 
mulheres. (PDT, 1999).

Com relação à menção às categorias "gênero" e "mulher", apenas quatro partidos (PC do B, PSOL, PT e PPS) incluem a primeira em seus estatutos, enquanto a segunda é incluída em 13 dos 22 documentos analisados, quais sejam os estatutos dos partidos PDT, PC do B, PP, PSOL, PTB, PT, DEM, PPS, PT do B, PRTB, PSB, PSDB, PV. A seguir, citamos alguns artigos dos estatutos para ilustrar esse resultado:

Estatuto do PT - Artigo 14, inciso II: Combater todas as manifestaçôes de discriminação em relação à etnia, aos portadores de deficiência física, aos idosos, assim como qualquer outra forma de discriminaçáo social, de gênero, de orientação sexual, de cor ou raça, idade ou religião [...]. (PT, 2007).

Estatuto do PPS - Artigo 12, inciso VIII: ter respeitada a sua situação socioeconômica e suas condiçốes de gênero, cor, raça, idade, estado e capacidade civil, de ser portador de necessidades especiais, bem como sua opção de credo religioso e livre orientação sexual. (CIDADANIA, 2009).

Estatuto do PDT - Artigo $1^{\circ}, \$ 1^{\circ}$ : lutar pela causa da mulher, do negro, do índio, dos jovens e dos idosos, sem qualquer forma de discriminaçáo [...]. (PDT, 1999).

Estatuto do DEM - Artigo 109, $\$ 3^{\circ}$ : O Democratas dará ênfase à participaçáo de jovens e mulheres no processo eleitoral. (DEM, 2008).

Estatuto do PTdoB (atual Avante) - Artigo 52: O Partido através de seu Diretório poderá constituir conselhos que funcionarão por regimento próprio a saber: juventude, mulher, comunicação e propaganda, ação sindical e formação política. (AVANTE, 1996).

Finalmente, verificamos que em 17 estatutos (PDT, PR, PCdoB, PRP, PP, PSOL, PTB, PT, DEM, PPS, PSC, PTdoB, PSB, PSDB, PV, PSL, PTC) há menção a algum princípio amplo de não-discriminação, em que o partido manifesta combater todas as formas de discriminação ou preconceito, sem, no entanto, mencionar especificamente a dimensão de gênero, como indicam os trechos abaixo:

Estatuto do PSC - Artigo 2o: O PSC reger-se-á, inciso I: por este estatuto e tem como fundamento a doutrina social cristá, onde o cristianismo, mais 
do que uma religião, representa um estado de espírito que não segrega, não exclui, nem discrimina, mas que aceita a todos independentemente de credo, cor, raça, ideologia, sexo, condição social, política, econômica ou financeira. Artigo 31: Os órgãos do PSC não intervirão nos hierarquicamente inferiores, exceto para, inciso I: garantir o direito das minorias. (PSC, 2007).

Estatuto do PTdoB - Artigo 10: O PARTIDO TRABALHISTA DO BRASIL, PT do B, é um partido político, Entidade de Âmbito Nacional, integrado por todos os brasileiros que nele se inscrevem, aceitando seu programa, regendo-se por seu Estatuto, sem restriçóes de qualquer ordem: sexual, social, econômica ou religiosa. Artigo 49: Os órgãos do Partido não intervirão nos hierarquicamente inferiores, salvo para, inciso V: Garantir o direito das minorias. (AVANTE, 1996).

No tocante à categoria ação afirmativa, visamos identificar se os estatutos mencionam órgão de mulheres e se detalham seu funcionamento. Nossa busca nos documentos se pautou pela descrição de a) composição dos órgãos, b) critérios para participação, c) objetivos dessa instância intrapartidária, d) previsão de autonomia jurídica e/ou financeira, e) informaçóes sobre a destinação de recursos às mulheres, como percentual do fundo partidário e creche, f) informaçóes sobre açóes de treinamento e capacitação para mulheres e g) menção sobre sanção para descumprimento de tais ações.

Há menção a órgãos de mulheres em 15 dos 22 estatutos analisados: PDT, PCdoB, PP, PSL, PSOL, PTB, PT, DEM, PPS, PTdoB, PRTB, PSB, PSDB, PV, PTC. Entretanto, essa mençáo náo é acompanhada de detalhamento do funcionamento do órgão, o que incluiria informaçôes sobre autonomia jurídica e financeira, critérios para composição, financiamento, objetivo e forma de atuação. Tais lacunas podem indicar um baixo grau de formalização ou institucionalização de tais instâncias, o que deve ser verificado por meio de novas pesquisas.

Com relação às demais estratégias de ação afirmativa, como a reserva de um percentual do fundo partidário para os órgãos de mulheres e a existência de açóes de treinamento e formação de lideranças femininas, não há informaçôes, o que pode, por um lado, reforçar os achados de Monzoy (2011) e Roza, Llanos e Garzón de la Roza (2010), que indicam que a atuação dessas organizaçôes é comprometida pela ausência de recursos, o que mitiga seu efeito como ação afirmativa. Mais uma vez, a não existência de informaçóes a esse respeito nos estatutos deve ser tomada como ponto de partida para pesquisas futuras, baseadas em estudos de caso que permitam analisar as 
dinâmicas intrapartidárias. Infelizmente, essa análise foge ao escopo deste artigo.

Por fim, quanto à discriminaçáo positiva, procuramos identificar aspectos relativos à reserva de vagas nas Comissóes Executivas Nacionais (CEN). Como apontam Ribeiro (2013) e Pinho (2016), as comissóes executivas concentram importantes prerrogativas decisórias, destacando-se como aquela instância que responde pelo partido em suas atividades cotidianas. Diante disso, observamos se havia políticas de discriminação positiva previstas pelos estatutos e também o percentual de mulheres presentes nessas instâncias.

A partir da análise dos estatutos dos partidos políticos que compuseram nossa amostra, verificamos que apenas PDT (20\%) ${ }^{10}$, PPS (30\%), PSB (30\%) e PT (30\%) adotaram voluntariamente esse mecanismo, destinando um percentual das vagas na executiva nacional às mulheres. As legendas PV, PSDB, PROS, PTB e SD reservam uma vaga para mulheres na Executiva Nacional, relativa à Secretaria da Mulher. O PCdoB menciona o incentivo à eleição de mulheres para tais órgáos em seu estatuto, sem definir, no entanto, como ele se materializaria.

A Tabela 3, a seguir, apresenta dados relativos à composição das CENs, destacando o percentual de mulheres presentes nesses órgãos.

Tabela 3 - Número de membros, número de membros mulheres e percentual de mulheres nas executivas nacionais dos partidos brasileiros anterior à eleição de 2010

\begin{tabular}{l|c|c|c}
\hline \multicolumn{1}{c|}{ Partido } & Node Membros Executiva & No de Mulheres $^{\circ}$ & \% de Mulheres \\
\hline DEM & 58 & 6 & 10,34 \\
\hline PCdoB & 29 & 7 & 24,14 \\
\hline PDT & 36 & 3 & 8,33 \\
\hline PHS & 29 & 4 & 13,79 \\
\hline PMDB & 26 & 1 & 3,85 \\
\hline PMN & 18 & 5 & 27,78 \\
\hline PP & 215 & 22 & 10,23 \\
\hline PPS & 26 & 7 & 26,92 \\
\hline PR & 52 & 4 & 7,69 \\
\hline PRB & 22 & 5 & 22,73 \\
\hline PRP & 46 & 13 & 28,26 \\
\hline PRTB & 14 & 4 & 28,57 \\
\hline PSB & 50 & 2 & 18 \\
\hline PSC & 20 & 2 & 10 \\
\hline
\end{tabular}

${ }^{10}$ No artigo 26 do estatuto analisado, são reservadas $30 \%$ das vagas em órgãos partidários e listas eleitorais para mulheres, enquanto no artigo 83 o percentual mencionado é de $20 \%$. 
54 | Daniela Rezende, Rayza Sarmento e Louise Tavares

\begin{tabular}{l|c|c|c}
\hline PSDB & 38 & 4 & 10,52 \\
\hline PSL & 26 & 3 & 11,54 \\
\hline PSOL & 18 & 1 & 5,55 \\
\hline PT & 27 & 8 & 29,63 \\
\hline PTdoB & 17 & 1 & 5,88 \\
\hline PTB & 102 & 10 & 9,8 \\
\hline PTC & 40 & 13 & 32,5 \\
\hline PV & 60 & 11 & 18,33 \\
\hline TOTAL & 1041 & 163 & 17,02 \\
\hline
\end{tabular}

Fonte: Elaborado pelas autoras a partir de dados do TSE.

O percentual médio de mulheres nas CENs é de 17,02\%. O PMDB e o PTN destacam-se, respectivamente, como partidos com o menor $(3,85 \%)$ e o maior (36,36\%) percentual de mulheres em seu órgão decisório máximo. Dos partidos que prevêem um percentual de reserva de vagas para mulheres no CEN, apenas o PPS consegue cumprir o estabelecido em seu estatuto.

Sabemos que esses dados explicitam o fato de que uma análise circunscrita aos estatutos apresenta certos limites. A pesquisa documental não nos permite obter informações substantivas referentes à "dinâmica real de poder no interior das agremiaçôes” (RIBEIRO, 2013, p. 254). Ainda assim, os dados apresentados aqui devem ser tomados como uma primeira aproximaçáo da dinâmica partidária, contribuindo para o levantamento ou refinamento de hipóteses mais que para o estabelecimento de conclusôes. Nesse sentido, incorporamos como fonte de dados os sítios eletrônicos dos órgãos de mulheres vinculados aos partidos políticos brasileiros. O detalhamento da análise e a discussão dos resultados são apresentados na próxima seção.

\section{Análise dos sites partidários}

Para a análise dos sítios eletrônicos dos órgãos de mulheres foi necessário realizar algumas adaptaçóes. A primeira delas se refere ao recorte temporal da pesquisa, uma vez que a coleta de dados dos estatutos e dos sítios eletrônicos foi circunscrita ao ano de 2010, em que foram realizadas eleiçóes para a 54a legislatura. Para analisar os sítios eletrônicos relativos a esse período, recorremos ao "Internet archive: wayback machine" (https://archive.org/web/). Trata-se de uma organização sem fins lucrativos, destinada a armazenar arquivos de recurso multimídia. Os arquivos podem ser salvos por qualquer pessoa e são identificados pela data em que ocorreu a captura e hospedados no endereço https://archive.org/web/, cujo formato se assemelha a uma 
biblioteca de objetos virtuais.

Com base nesse recurso, foi-nos possível investigar se algum dos partidos de nosso interesse teve seu domínio salvo em períodos próximos à data em que ocorreram as eleiçóes no ano de 2010. Feito isso, procedemos à procura por domínios independentes de órgãos de mulheres nos sítios eletrônicos arquivados no wayback machine. Essa etapa, todavia, apresentou alguns percalços, uma vez que não encontramos arquivos de todos os partidos políticos de nosso interesse, assim como nos deparamos com enorme dificuldade em acessar os conteúdos de alguns dos sítios eletrônicos lá arquivados.

O segundo constrangimento ao trabalho e à coleta de dados se referiu à inexistência de sítios eletrônicos de órgãos de mulheres em muitos dos casos pesquisados. Em alguns desses (PSDB, PRTB, PSB, PTB, PCdoB, PDT, PMDB, PT, PRB) foram disponibilizados links para informaçôes sobre órgãos de mulheres nos sites dos partidos, sem haver um sítio eletrônico específico para o setorial de mulheres; em outro (PSOL), o link existia, mas levava a uma seção de notícias sobre o setorial de mulheres; para os partidos PRP, PHS, PR, PSC, PTC e PTdoB, náo foi encontrado endereço eletrônico relativo ao período analisado. Optamos por analisar o material disponível, totalizando 14 casos, apresentados na Tabela 2 já exibida.

A análise de sites de partidos políticos tem se configurado em plano nacional e internacional como um veio das pesquisas em democracia digital, em especial preocupadas com as dimensôes institucionais ou com a "conformação digital das instituiçóes da democracia" (SILVA et al., 2016, p. 20). Estudos como o clássico desenvolvido por Norris (2003), com a análise de 134 sites de partidos da União Europeia, procuram demonstrar como a presença digital pode favorecer maiores oportunidades de interação e tornar mais igualitários os padrões de comunicação entre grandes, médios e pequenos partidos quando comparado ao espaço que possuem na mídia tradicional. Já a discussão de Schweitzer (2008), tem sido mobilizada para pensar até que ponto há inovaçóes na competição política disponível na internet ou se ocorrem processos de normalização, com a negligência dos espaços interativos pelos partidos e aposta nas formas convencionais de publicidade política. No Brasil, vale destacar os robustos trabalhos de Braga et al. (2009) e Braga, Rocha e Carlomagno (2015) com a medição de um conjunto de variáveis sobre a presença on-line dos partidos políticos de forma comparativa, a partir de características como a disponibilização de informaçôes, ferramentas de interatividade e engajamento, mobilização e o grau de sofisticação dessas páginas, além de navegabilidade e usabilidade das páginas. Braga, Rocha e Carlomagno 
(2015, p. 51) têm mostrado que os partidos têm "usado amplamente a internet" e privilegiado a oferta de informaçóes.

Entretanto, mesmo sendo uma questão fértil de pesquisas, quando comparados a outros "objetos políticos" do campo de estudos da internet e política, como as iniciativas digitais dos governos ou mesmo o ativismo digital, os partidos ainda têm tido pouca atenção. Estudo de Sampaio et al. (2016) com os trabalhos dos principais eventos da área (universo de 526 artigos) evidencia que apenas 1,9\% dos trabalhos focam nas iniciativas virtuais das legendas brasileiras. Dessa forma, entendemos que há muito o que ser explorado na utilização da internet pelos partidos.

No tocante à forma como os órgãos de mulheres aparecem (ou não) nos sites partidários ou em páginas específicas, as pesquisas ainda são mais raras. No trabalho de Braga et al. (2009), por exemplo, links para o que os autores chamam de "núcleos de mulher" estão dentro do conjunto de variáveis chamado de "estrutura decisória e recrutamento" e se apresentam em 51,9\% das páginas dos 27 partidos investigados na época. Na pesquisa de Norris (2003), as women's sections são entendidas a partir de sua função de informaçáo, tal como os links sobre a história dos partidos. Rocha (2014) observa a presença de "organizaçôes sindicais/estudantis/mulheres/gênero", de forma agrupada, sob o viés da mobilizaçáo. Nota-se como os órgáos de mulheres náo têm tido merecida atenção dentro da configuração partidária no âmbito on-line e off-line, o que justifica de sobremaneira uma aproximação exploratória com esses dados.

Diante dos limites dos dados encontrados, apontados acima, a avaliação dos sítios eletrônicos a partir da criação de índices, tais como aquele utilizado por Rocha (2014), se mostrou inviável, dada a diversidade dos formatos utilizados pelas seçóes de mulheres dos partidos políticos brasileiros, indicada na Tabela 2, disposta anteriormente. Dessa forma, optamos apenas por descrever o material encontrado, o que já pode dar pistas importantes sobre os órgãos de mulheres dos partidos políticos brasileiros.

Nesse sentido, adaptamos a metodologia utilizada por Rocha $(2014)^{11}$ e, a partir dessas fontes de dados, foi possível coletar informaçóes sobre a organização dos órgãos de mulheres que não estavam disponíveis nos estatutos, tais como: data de criação do órgão, formato adotado (secretaria, departamento, setorial etc.), o nome da responsável pelo órgão. Esses dados são detalhados a seguir, na Tabela 4.

\footnotetext{
${ }^{11}$ Rocha (2014) ancora sua investigação em variáveis que já foram testadas em outros estudos (BRAGA et al., 2015), tendo como referência quatro eixos: 1) difusão de informação; 2) interação; 3) mobilização; e 4) sofisticação.
} 
Tabela 4 - Informaçôes disponíveis nos endereços eletrônicos analisados

\begin{tabular}{|c|c|c|c|c|c|c|}
\hline Partido & $\begin{array}{l}\text { Tipo endereço } \\
\text { eletrônico }\end{array}$ & Tipo & Programa & História & Documentos & Calendário \\
\hline DEM & Site próprio & $\begin{array}{l}\text { Órgão de açáo } \\
\text { partidária }\end{array}$ & Não & Não & Não & Sim \\
\hline PCdoB & $\begin{array}{l}\text { Link no site do } \\
\text { partido }\end{array}$ & Secretaria & Sim & Sim & Náo & Não \\
\hline PDT & $\begin{array}{l}\text { Link no site do } \\
\text { partido }\end{array}$ & Movimento & Sim & Não & Não & Náo \\
\hline PMDB & $\begin{array}{l}\text { Link no site do } \\
\text { partido }\end{array}$ & Núcleo & Não & Não & Não & Não \\
\hline PMN & Site próprio & $\begin{array}{l}\text { Departamento } \\
\text { Feminino }\end{array}$ & Sim & Sim & Não & Sim \\
\hline PP & Site próprio & $\begin{array}{l}\text { Executiva } \\
\text { Nacional }\end{array}$ & Sim & Sim & Sim & Sim \\
\hline PPS & Site próprio & $\begin{array}{c}\text { Coordenação } \\
\text { nacional }\end{array}$ & Sim & Sim & Sim & Não \\
\hline PRB & $\begin{array}{l}\text { Link no site do } \\
\text { partido }\end{array}$ & Militância & Náo & Não & Não & Não \\
\hline PRTB & $\begin{array}{l}\text { Link no site do } \\
\text { partido }\end{array}$ & $\begin{array}{l}\text { Secretaria da } \\
\text { Mulher }\end{array}$ & Não & Não & Não & Não \\
\hline PSB & $\begin{array}{l}\text { Link no site do } \\
\text { partido }\end{array}$ & $\begin{array}{l}\text { Secretaria da } \\
\text { Mulher }\end{array}$ & Sim & Sim & Sim & Não \\
\hline PSDB & $\begin{array}{l}\text { Link no site do } \\
\text { partido }\end{array}$ & $\begin{array}{l}\text { Secretariado } \\
\text { Nacional }\end{array}$ & Sim & Sim & Sim & Não \\
\hline PT & $\begin{array}{l}\text { Link no site do } \\
\text { partido }\end{array}$ & $\begin{array}{l}\text { Secretaria } \\
\text { Nacional }\end{array}$ & Sim & Não & Náo & Sim \\
\hline PTB & $\begin{array}{c}\text { Link no site do } \\
\text { partido }\end{array}$ & $\begin{array}{l}\text { Executiva } \\
\text { Nacional }\end{array}$ & Sim & Não & $\operatorname{Sim}$ & Não \\
\hline PV & Site próprio & $\begin{array}{l}\text { Secretaria da } \\
\text { Mulher }\end{array}$ & Sim & Sim & $\operatorname{Sim}$ & Sim \\
\hline
\end{tabular}

Fonte: Elaborado pelas autoras.

A Tabela 4 mostra que há grande diversidade nos formatos adotados pelos órgãos de mulheres, predominando, no entanto, as secretarias. A tabela indica ainda que, em muitos casos, náo foram encontradas informaçóes mais detalhadas sobre o funcionamento desses órgãos, infraestrutura e recursos. Em 10 dos 14 endereços eletrônicos analisados, são apresentados os programas do órgão de mulheres (PMN, PSDB, PP, PSB, PTB, PV, PCdoB, PDT, PT, PPS). Em sete sites, metade do total analisado, a história do órgão é apresentada (PMN, PSDB, PP, PSB, PV, PCdoB, PPS). Em seis deles são disponibilizados documentos para consulta (PSDB, PP, PSB, PTB, PV e PPS) e em apenas cinco, um calendário de atividades (PMN, PP, PV, 
DEM, PT).

Entretanto, os dados sobre a presidência e composição, dispostos na Tabela 5 , fornecem mais algumas pistas sobre essas organizaçóes.

Tabela 5 - Presidência e número de membros dos órgãos partidários de mulheres

\begin{tabular}{l|c|c}
\hline \multicolumn{1}{c|}{ Partido } & Presidenta & Número de membros \\
\hline DEM & Solange Amaral & 9 \\
\hline PCdoB & Liége Rocha & 5 \\
\hline PDT & Miguelina Vecchio & 17 \\
\hline PMDB & Não informado & Não informado \\
\hline PMN & Myrian Aparecida Bosco Massarollo & 17 \\
\hline PP & Maria Elizabeth Pelegrini Tiscoski & Não informado \\
\hline PPS & Não informado & Não informado \\
\hline PRB & Não informado & Náo informado \\
\hline PRTB & Aldinea Rodrigues Fidelix da Cruz & Não informado \\
\hline PSB & Dora Pires & Não informado \\
\hline PSDB & Thelma de Oliveira, dep. federal & 18 \\
\hline PT & Laysi Moriére & Não informado \\
\hline PTB & Cristiane Brasil, dep. federal & Não informado \\
\hline PV & Regina Gonçalves & Não informado \\
\hline
\end{tabular}

Fonte: Elaborado pelas autoras.

Em primeiro lugar, para três partidos ( $\mathrm{PMDB}$, $\mathrm{PPS}$ e $\mathrm{PRB}$ ) não havia informaçôes sobre quem ocupava a presidência do órgáo em 2010, e apenas para DEM, PCdoB, PMN, PP e PSDB foram disponibilizadas informações sobre a composição desse órgáo. A indisponibilidade de tais dados pode indicar uma fragilidade organizacional ou baixo grau de institucionalização desses órgãos, o que pode comprometer sua atuação e efetividade.

Com relação às presidências dos órgãos, três delas eram ocupadas por deputadas federais (DEM, PSDB e PRB), uma por candidata ao Senado com vínculos familiares com políticos (PP), uma pela esposa do presidente do partido (PRTB), uma secretária estadual da mulher (PSB), uma por mulher com trajetória na política municipal, nos poderes Executivo e Legislativo (PV), além de três mulheres envolvidas com movimentos de mulheres (PCdoB, PDT e PT). No caso do PMN, não foi identificada a trajetória política prévia da presidenta.

Esse também pode ser um indicador relevante a respeito do tipo de atuação do órgão partidário de mulheres: se voltado ao recrutamento de militantes e lideranças, se voltado à promoção de mulheres já eleitas, por exemplo. Importante mencionar que a 
centralidade desse dado diz respeito não apenas à representação de mulheres, mas também às características organizacionais dos partidos, sobretudo no que se refere à distribuição de cargos e recursos políticos.

Para além de dados sobre a organização, história e funcionamento do órgão, elegemos e adaptamos alguns elementos e conteúdos presentes na análise de Norris (2003) para tentar entender o uso dos websites pensando em processos de interação e informação proporcionados pela dimensão on-line. Selecionamos cinco elementos para observação, são eles: a) a disponibilizaçáo da ficha de filiação do partido, como uma característica fundamental de mobilização de adeptos; b) a presença de contatos específicos dos órgãos de mulheres, considerando telefones, endereços e e-mails (um ou mais); c) a possibilidade de assinatura de newsletterou informativos específico sobre a atuação dos órgãos; d) a veiculação de notícias sobre representação feminina; e e) a presença de links para organizaçóes ou movimentos de mulheres. A Tabela 6 descreve nossos achados.

Tabela 6 - Conteúdos disponíveis nos endereços eletrônicos analisados

\begin{tabular}{l|c|c|c|c|c}
\hline Partido & $\begin{array}{c}\text { Ficha de } \\
\text { filiaçáo } \\
\text { geral }\end{array}$ & $\begin{array}{c}\text { Contatos específicos - } \\
\text { telefones/endereços/email }\end{array}$ & $\begin{array}{c}\text { Newsletter/ } \\
\text { Informativos }\end{array}$ & $\begin{array}{c}\text { Notícias sobre } \\
\text { representaçáo } \\
\text { feminina }\end{array}$ & $\begin{array}{c}\text { Links para } \\
\text { organizaçóes } \\
\text { ou } \\
\text { movimentos } \\
\text { de mulheres }\end{array}$ \\
\hline DEM & Sim & Sim & Sim & Sim & Não \\
\hline PCdoB & Sim & Sim & Não & Sim & Não \\
\hline PDT & Sim & Não & Não & Não & Não \\
\hline PMDB & Sim & Sim & Não & Não & Não \\
\hline PMN & Não & Sim & Não & Não & Não \\
\hline PP & Não & Sim & Não & Sim & Não \\
\hline PPS & Sim & Náo & Não & Sim & Não \\
\hline PRB & Sim & Não & Não & Não & Não \\
\hline PRTB & Náo & Não & Não & Não & Sim \\
\hline PSB & Não & Não & Não & Sim & Não \\
\hline PSDB & Sim & Sim & Sim & Sim & Não \\
\hline PT & Não & Náo & Sim & Sim & Sim \\
\hline PTB & Não & Sim & Náo & & \\
\hline PV & Sim & & &
\end{tabular}

Fonte: Elaborado pelas autoras.

Dos cinco elementos analisados nos sites ou páginas dos órgãos de mulheres, os mais comuns são links/botôes com a ficha de filiação geral do partido e notícias sobre representação feminina a partir de fatos envolvendo, majoritariamente, as eleitas 
por aquela legenda.

Outro dado descritivo importante a partir dessa observação das páginas é que apenas a metade dos partidos apresenta um contato (seja endereço, telefones ou emails) específico para o seu órgão de mulher. Isso se torna relevante para pensar a autonomia desses mecanismos dentro dos partidos e para formas de acesso de futuras interessadas em participar desses órgãos. Newsletter ou informativos específicos sobre a atuação das representantes femininas só estiveram disponíveis em três das catorze páginas analisadas. Esse recurso é importante na visibilidade das açôes das mulheres dentro dos partidos. Outro dado que chama atenção é que apenas em três sites, os do PSB, PT e PV, há links para organizaçóes ou movimentos de mulheres, relação que pode influenciar de forma positiva a elegibilidade de mulheres, como apontam Santos, Paula e Seabra (2012).

Apenas uma página, a do PRTB, não apresentou nenhum dos critérios, e o DEM foi a legenda que apresentou o maior número deles. A maior parte dos partidos apresentou três critérios, tais como PP, PSDB e PTB, cujas homepages abaixo atestam. 
Figura 1 - Homepage do Mulher Progressista em 20/06/2010

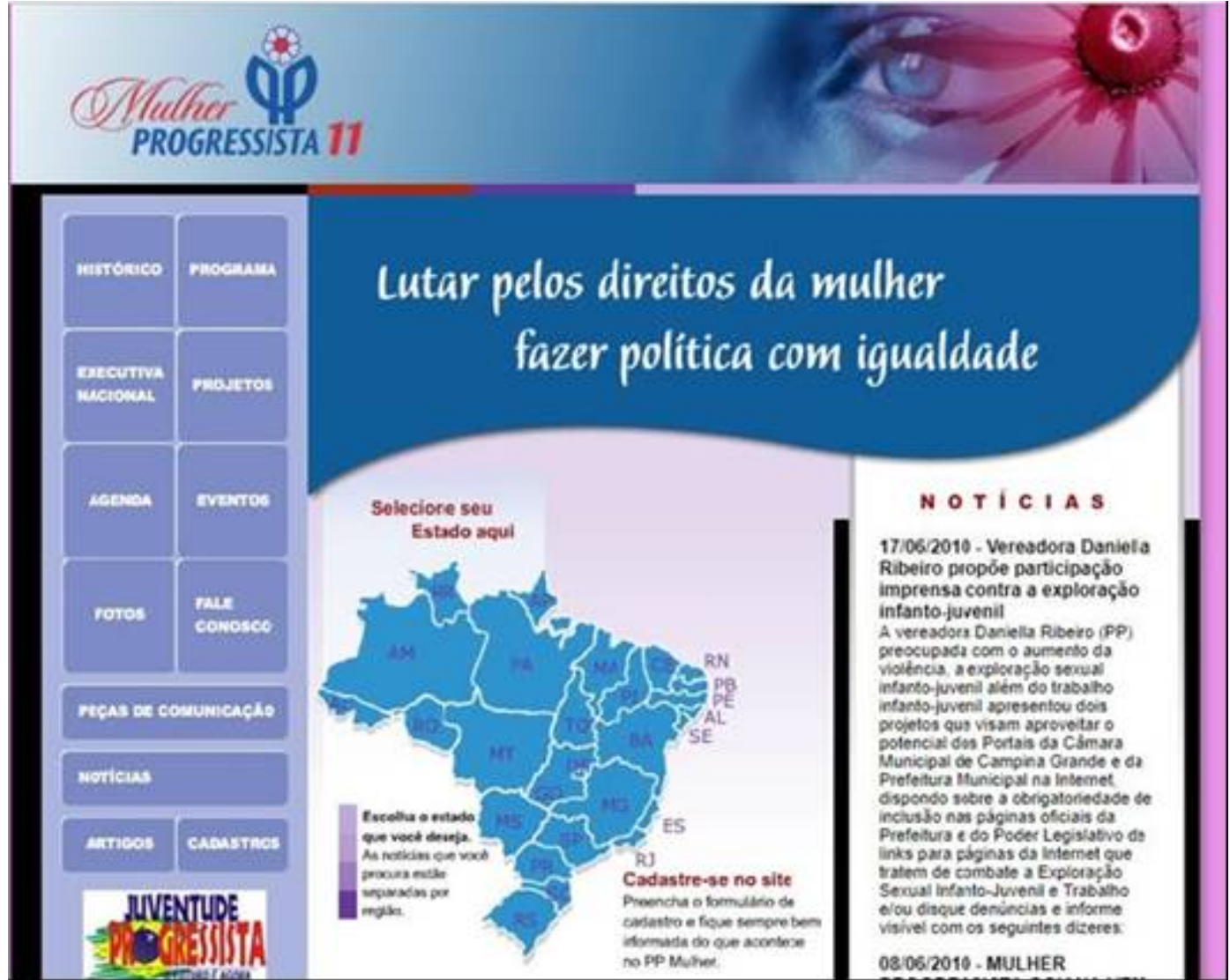

Fonte: Partido Progressista (2010). 
62 | Daniela Rezende, Rayza Sarmento e Louise Tavares

Figura 2 - Homepage do PSDB Mulher em 12/09/2010

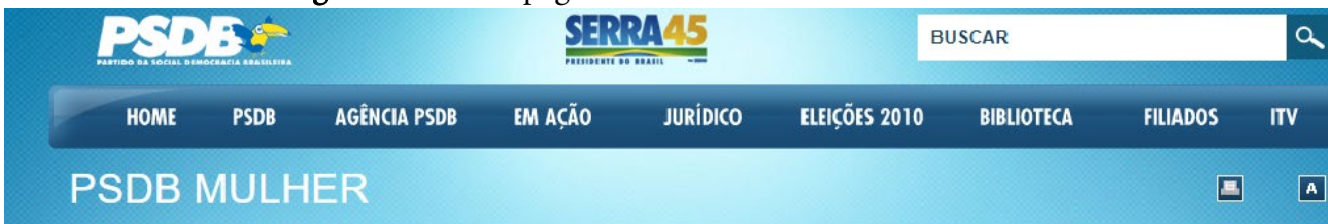

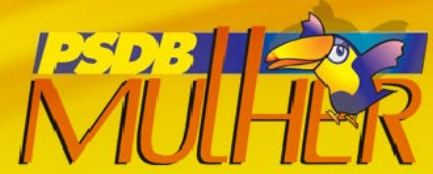

COMO FIUAR-SE AO PSDB-MULER

COMO MONTAR Un

\section{PSDB MULHER}

Discurso de Serra com Prefeitos - 02/09 em São Paulo

Íntegra do discurso de Serra: "Não preciso de marqueteiro que mude a

minha cara, o meu pensamento, a minha trajetória de vida" Leia mais

\section{PSDB MULHER}

\section{ENTREVISTA COM MÔNICA SERRA}

Mônica Serra em entrevista exemplar: "É isso que fazem as ditaduras; já

vi meu filho de 9 meses com um cano de arma na cabeça"

(Por Catia Seabra, na Folha:)

Leia mais "

Fonte: PSDB (2010). 
Figura 3 - Homepage do PTB Mulher (PTB) em 08/08/2010

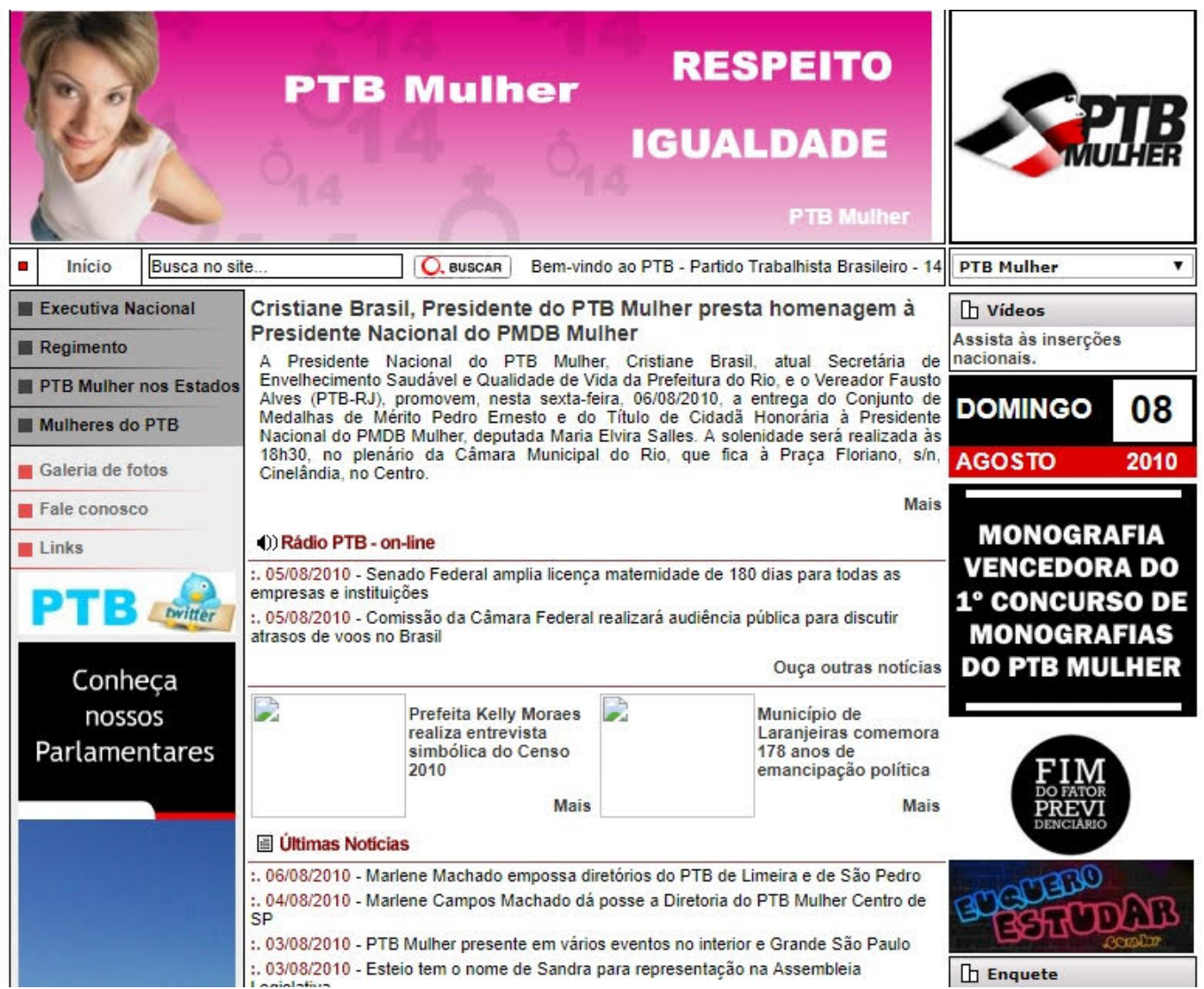

Fonte: PTB (2010).

Esses dados apontam para inconsistências no uso dos websites por partidos, considerando sua classificação no continuum esquerda-direita, o que reforça o argumento apresentado por Caul (2013) e Santos, Paula e Seabra (2012) de que essa classificação precisa ser refinada para captar de forma mais adequada possíveis diferenças na atuação dos partidos com relação à inclusão política de mulheres. Os resultados também apontam para a necessidade de considerar outras estratégias de comunicação adotadas pelos órgáos de mulheres nos partidos, tal como o recurso às redes sociais, uma vez que o uso de websites como ferramenta se mostrou muito limitado. 
A análise dos sítios eletrônicos, em conjunto com os estatutos, mesmo com limites metodológicos, sugere que os órgãos de mulheres não são efetivos como estratégia de inclusão de mulheres nos partidos, dada sua debilidade organizacional e os poucos esforços concentrados nas ações de comunicação via websites. Se os estudos sobre a presença on-line de partidos políticos têm cogitado que "[...] a internet agrega algo de novo ao processo partidário, náo podendo ser considerada mera ferramenta de reprodução de padrôes offline" (BRAGA et al., 2015, p. 69), o mesmo parece não ocorrer quando olhamos especificamente para a forma como essas estruturas específicas de recrutamento e organização de mulheres aparecem. No caso dos órgãos de mulheres, parece haver mais normalização do que inovação, nos termos de Schweitzer (2008). Como a própria autora pontua, o status prévio dos atores políticos colabora para a compreensão da forma como se colocam visíveis e engajados em âmbito online. No caso das mulheres, essa pesquisa exploratória sugere que a pouca organicidade dos órgãos também se mostra aguda nas páginas on-line, o que já havia sido verificado também na análise dos estatutos.

\section{Considerações finais}

Este texto avaliou se a existência de órgãos de mulheres nos partidos políticos pode ser classificada como uma ação afirmativa ou se indica apenas uma estratégia retórica, com eficácia limitada no que se refere ao incremento da representação política de mulheres no Brasil. A metodologia da pesquisa compreendeu a 1) análise documental, tendo como objeto os estatutos dos partidos disponíveis no sítio eletrônico do TSE; e a 2) análise dos sítios eletrônicos dos órgãos de mulheres vinculados aos partidos políticos. A amostra foi composta por 22 partidos na análise documental e 14 partidos na análise de websites, devido à escassez de sítios eletrônicos voltados às organizaçóes de mulheres.

O conjunto das análises realizadas, considerando desde o estudo dos estatutos dos partidos políticos, a análise dos websites dos órgãos de mulheres e sua relação com a eleição de deputadas para a Câmara dos Deputados, indica que os órgãos de mulheres têm atuaçáo limitada, o que aponta para seu caráter predominantemente retórico. Ainda que se trate de uma análise descritiva, a conclusáo deve ser tomada como hipótese para pesquisas futuras, que possam contar com recursos adequados para um levantamento de dados mais compreensivos sobre tais organizaçóes.

Além disso, os resultados apontam que o uso de websites pelos órgáos partidários de mulheres é muito limitado, concentrando-se nas açôes de difusão da informação. Isso explicita os limites da metodologia aqui adotada, mas também pode 
sugerir que os órgãos de mulheres não são efetivos como estratégia de inclusão de mulheres nos partidos, dada sua debilidade organizacional e os poucos esforços concentrados nas açóes de comunicação via website. Ademais, a investigação apresentada reforça a importância da realizaçáo de pesquisa de campo, de caráter qualitativo, de forma a produzir informaçóes mais acuradas e consistentes sobre os órgãos partidários de mulheres.

Finalmente, reforçamos a relevância de desenvolver pesquisas sobre as organizaçóes partidárias, considerando os partidos políticos e a forma como se estruturam como objeto de análise. Nesse sentido, ainda que voltada à análise específica de órgáos partidários, a pesquisa realizada pode contribuir para elucidar questóes mais amplas, relacionadas a atividades partidárias fundamentais, como o recrutamento de militantes e lideranças e a mobilização política.

- Daniela Rezende é Doutora em Ciência Política, pela Universidade Federal de Minas Gerais (UFMG). Professora no Departamento de Ciências Sociais da Universidade Federal de Viçosa (UFV). Coordenadora e membro do Núcleo Interdisciplinar de Estudos de Gênero da mesma instituição. E-mail: danielal.rezende@ufv.br.

- Rayza Sarmento é Doutora em Ciência Política, pela UFMG. Professora no Departamento de Ciências Sociais da UFV. Coordenadora do Grupo de Pesquisa em Gênero, Comunicação, Democracia e Sociedade (GCODES). E-mail: rsarmento@ufv.br.

Louise Tavares é Bacharel em Ciências Sociais, pela UFV. E-mail: tavares.louises@gmail.com.

\section{Referências}

ÁLVARES, Maria Luzia. Mulheres brasileiras em tempo de competição eleitoral: seleção de candidaturas e degraus de acesso aos cargos parlamentares. Dados, v. 51, n. 4, p. 895-940, 2008.

ARAÚJO, Clara. Partidos políticos e gênero: mediaçóes nas rotas de ingresso das mulheres na representação política. Revista de Sociologia e Política, n. 24, p. 193-215, 2005.

AVANTE. Estatuto do PTdoB/AVANTE (1996). Aprovado em 06 de abril de 1996. Brasília, 1996. 
Disponível em: <http://www.justicaeleitoral.jus.br/arquivos/estatuto-do-partido-trabalhista-do-brasilde-6-4.1996>. Acesso em: 11 dez. 2020.

BARREIRA, Irlys Alencar; GONÇALVES, Danyelle N. "Presença" e "ausência" de candidatas: mapeando representaçôes de dirigentes partidários. In: ALVES, José Eustáquio D.; PINTO, Céli Regina J.; JORDÁO, Fátima. (Orgs.). Mulheres nas eleiçôes 2010. São Paulo: ABCP/Secretaria de Políticas para as Mulheres, 2012. p. 315-336.

BRAGA, Sérgio; ROCHA, Leonardo C.; CARLOMAGNO, Márcio C. A internet e os partidos políticos brasileiros. Cadernos Adenauer, v. XVI, n. 3, p. 47-73, 2015.

BRAGA, Sérgio et al. Os partidos políticos brasileiros e a internet: uma avaliação dos websites dos partidos políticos do Brasil. Revista de Sociologia e Política, v. 17, p. 183-208, 2009.

BRASIL. Tribunal Superior Eleitoral. Partidos políticos registrados no TSE. Portal do TSE, s/d. Disponível em: <http://www.tse.jus.br/partidos/partidos-politicos/registrados-no-tse>. Acesso em: 08 dez. 2020.

CAUL, Miki. Party politics. In: WAYLEN, Georgina (Ed.). The Oxford handbook of gender and politics. Oxford University Press, 2013. p. 536-553. [e-book].

CAUL, Miki. Women, parties and platforms in post-industrial democracies. Party Politics, v. 17, n. 1, p. 66-92, 2011.

CAUL, Miki. Political parties and the adoption of candidate gender quotas: A cross-national analysis. Journal of Politics, v. 63, n. 4, p. 1214-1229, 2001.

CAUL, Miki. Women's Representation in Parliament The Role of Political Parties. Party Politics, v. 5, n. 1, p. 79-98, 1999.

CAUL, Miki. Women's Representation in Parliament: The Role of Political Parties. Center for the Study of Democracy, 1997.

CIDADANIA. Estatuto do PPS/Cidadania (2009). Aprovado em 09 de agosto de 2009. Brasília, 2009.

Disponível em: <http://www.justicaeleitoral.jus.br/arquivos/tse-estatuto-do-partido-pps-9-8-2009resolucao-do>. Acesso em: 11 dez. 2020.

DEMOCRATAS. Estatuto (2007). Aprovado em 14 de agosto de 2008. Brasília, 2008. Disponível em: <https://www.justicaeleitoral.jus.br/arquivos/estatuto-do-partido-de-12-12-2007-resolucao-tseno.2008/rybena_pdf?file=https:/www.justicaeleitoral.jus.br/arquivos/estatuto-do-partido-de-12-122007-resolucao-tse-no.2008/at_download/file>. Acesso em: $11 \mathrm{dez} .2020$.

GIL, Antonio Carlos. Como elaborar projetos de pesquisa. 4. ed. São Paulo: Atlas, 2007.

LOVENDUSKI, Joni. Introduction. In: LOVENDUSKI, Joni; NORRIS, Pippa (Orgs.). Gender and party politics. Londres: Sage, 1993. p. 1-15.

MONZOY, Andira. Equidad de género y democracia interna de los partidos políticos: políticas partidistas para la inclusión política de las mujeres en Améria Latina. México: Tribunal Electoral del Poder Judicial de la Federación, 2011.

MOVIMENTO DEMOCRÁTICO BRASILEIRO (PMDB/MDB). Estatuto do PMDB/MDB (2007). Aprovado em 11 de março de 2007. Disponível em: $<$ https://www.justicaeleitoral.jus.br/arquivos/tse-estatuto-do-partido-de-11-3-2007-resolucaotse.112>. Acesso em: 11 dez. 2020.

NORRIS, Pippa. Recrutamento político. Revista de Sociologia e Política, v. 21, n. 46, p. 11, 2013.

NORRIS, Pippa. Preaching to the Converted? Pluralism, Participation and Party Websites. Party Politics, v. 9, n. 1, 2003, p. 21-45. 
O'BRIEN, Diana Z. Rising to the Top: Gender, Political Performance, and Party Leadership in Parliamentary Democracies. American Journal of Political Science, v. 59, n. 4, p. 1022-1039, 2015.

O'BRIEN, Diana Z. Gender and select committee elections in the British House of Commons. Politics \& Gender, v. 8, n. 2, p. 178-204, 2012.

PARTIDO COMUNISTA DO BRASIL (PCdoB). Estatuto do Partido Comunista do Brasil (2001). Aprovado em 12 de dezembro de 2001. Brasília, 2001. Disponível em: <http://www.justicaeleitoral.jus.br/arquivos/tse-estatuto-do-partido-de-9-a-12-12-2001.2006>.

Acesso em: 11 dez. 2020.

PARTIDO DA MOBILIZAÇÃO NACIONAL (PMN). Estatuto do PMN (2008). Aprovado em 06 de abril de 2008. Brasília, 2008. Disponível em: <http://www.justicaeleitoral.jus.br/arquivos/tseestatuto-do-partido-pmn-de-6-4-2008-resolucao-tse.2009>. Acesso em: 11 dez. 2020.

PARTIDO DEMOCRÁTICO TRABALHISTA (PDT). Estatuto do PDT (1999). Aprovado em 27 de agosto de $1999 . \quad$ Brasília, 1999. Disponível em: <https://www.justicaeleitoral.jus.br/arquivos/estatuto-do-partido-de-27-8-1999-resolucao-tseno.2000>. Acesso em: $11 \mathrm{dez} .2020$.

PARTIDO PROGRESSISTA (PP). Mulher Progressista. 2010. Disponível em: <https://web.archive.org/web/20100620191430/http://www.ppmulher.org.br/site/>. Acesso em: 09 dez. 2020.

PARTIDO PROGRESSISTA (PP). Estatuto do PP (2009). Aprovado em 02 de abril de 2009. Brasília, 2009. Disponível em: <http://www.justicaeleitoral.jus.br/arquivos/estatuto-do-partido-progressistade-2-4.2009>. Acesso em: $11 \mathrm{dez} .2020$.

PARTIDO DA SOCIAL DEMOCRACIA BRASILEIRA (PSDB). PSDB Mulher. 2010. Disponível em: <https://web.archive.org/web/20100912233621/http://www.psdb.org.br/index.php/emacao/psdb-mulher>. Acesso em: 09 dez. 2020.

PARTIDO DA SOCIAL DEMOCRACIA BRASILEIRA (PSDB). Estatuto do PSDB (2007). Aprovado em 23 de novembro de 2007. Brasília, 2007. Disponível em: $<$ http://www.justicaeleitoral.jus.br/arquivos/programa-partidario-psdb-resolucao-tse-no-23100.2009>. Acesso em: $11 \mathrm{dez} .2020$.

PARTIDO DOS TRABALHADORES (PT). Estatuto do PT (2007). Aprovado em 05 de outubro de 2007. Brasília, 2007. Disponível em: <https://www.justicaeleitoral.jus.br/arquivos/estatuto-dopartido-de-5-10-2007-resolucao-tse-no.2008>. Acesso em: 11dez. 2020.

PARTIDO LIBERAL (PR/PL). Estatuto do PR/PL (2009). Aprovado em 19 de abril de 2009. Brasília, 2009. Disponível em: <https://www.justicaeleitoral.jus.br/arquivos/estatuto-do-partido-da-republicade-19-04.2009>. Acesso em: 11 dez. 2020.

PARTIDO RENOVADOR TRABALHISTA BRASILEIRO (PRTB). Estatuto do PRTB (2004). Aprovado em 30 de janeiro de 2004. Brasília, 2004. Disponível em: <https://www.justicaeleitoral.jus.br/arquivos/estatuto-do-partido-renovador-trabalhista.2004>.

Acesso em: 11 dez. 2020.

PARTIDO SOCIAL CRISTÃO (PSC). Estatuto do PSC (2007). Aprovado em 01 de outubro de 2007. Brasília, 2007. Disponível em: <http://www.justicaeleitoral.jus.br/arquivos/tse-estatuto-do-partidopsc-de-1o-10-2007.2007>. Acesso em: $11 \mathrm{dez} .2020$.

PARTIDO SOCIALISMO E LIBERDADE (PSOL). Estatuto do PSOL (2004). Aprovado em 06 de 
junho de 2004. Disponível em: <https://www.justicaeleitoral.jus.br/arquivos/estatuto-do-partidosocialismo-e-liberdade-de-6-6.2004>. Acesso em: 11 dez. 2020.

PARTIDO SOCIALISTA BRASILEIRO (PSB). Estatuto do PSB (2008). Aprovado em 06 de junho de 2008. Brasília, 2008. Disponível em: <http://www.justicaeleitoral.jus.br/arquivos/tse-estatuto-dopartido-psb-de-6-6-2008-resolucao-tse-no-23-118-dj-de-21-9-2009>. Acesso em: $11 \mathrm{dez} .2020$.

PARTIDO SOCIAL LIBERAL (PSL). Estatuto do PSL (2004). Aprovado em 14 de fevereiro de 2004. Brasília, 2004. Disponível em: <https://www.justicaeleitoral.jus.br/arquivos/estatuto-do-partidosocial-liberal-de-14-2-2004.2006>. Acesso em: 11 dez. 2020.

PARTIDO TRABALHISTA BRASILEIRO (PTB). PTB Mulher. 2010. Disponível em: <https://web.archive.org/web/20100808051202/http://www.ptb.org.br:80/?estado=mu>. Acesso em: 09 dez. 2020.

PARTIDO TRABALHISTA BRASILEIRO (PTB). Estatuto do PTB (2009). Aprovado em 07 de março de 2009. Brasília, 2009. Disponível em: <https://www.justicaeleitoral.jus.br/arquivos/estatutodo-partido-7-3-2009-resolucao-no-23-065.2009>. Acesso em: 11 dez. 2020.

PARTIDO TRABALHISTA CRISTÁO (PTC). Estatuto do PTC (2008). Aprovado em 29 de abril de 2008. Brasília, 2008. Disponível em: <http://www.justicaeleitoral.jus.br/arquivos/tse-estatuto-dopartido-ptc-de-29-4-2008-resolucao.2008>. Acesso em: $11 \mathrm{dez} .2020$.

PARTIDO VERDE (PV). Estatuto do PV (2009). Aprovado em 03 de abril de 2009. Brasília, 2009. Disponível em: <http://www.justicaeleitoral.jus.br/arquivos/estatuto-do-partido-verde-de-3-4.2009>. Acesso em: $11 \mathrm{dez} .2020$.

PATRIOTA. Estatuto do PRP/PATRIOTA (2008). Aprovado em: 19 de junho de 2008. Brasília, 2008. PODEMOS (PHS/PODE). Estatuto do PHS/Pode (2009). Aprovado em 14 de novembro de 2009. Brasília, 2009. Disponível em: <https://www.justicaeleitoral.jus.br/arquivos/estatuto-do-partidohumanista-da-solidariedade-de-14-11-2009>. Acesso em: $11 \mathrm{dez} .2020$.

REPUBLICANOS. Estatuto do PRB/Republicanos (2008). Aprovado em 06 de fevereiro de 2008. Brasília, 2008. Disponível em: <https://www.justicaeleitoral.jus.br/arquivos/estatuto-do-partidorepublicano-brasileiro-de-6-2.2008>. Acesso em: 11 dez. 2020.

REZENDE, Daniela. Partidos políticos como instituiçóes generificadas. In: MARQUES, Danusa et al. (Orgs.). Feminismos em rede. Porto Alegre: Zouk, 2019. p. 193-208.

RIBEIRO, Pedro Floriano. Organização e poder nos partidos brasileiros: uma análise dos estatutos. Revista Brasileira de Ciência Politica, n. 10, p. 225-265, jan./abr. 2013.

ROCHA, Leonardo C. Os partidos na rede: ação política virtual das instituiçôes partidárias brasileiras. 2014. 140 f. Dissertação (Mestrado em Ciência Política) - Programa de Pós-Graduação em Ciência Política, Universidade Federal do Paraná, Curitiba, 2014.

ROZA, Vivian; LLANOS, Beatriz; GARZÓN DE LA ROZA, Gisela. Partidos politicos y paridad: La ecuación pendiente. Inter-American Development Bank, 2010.

SACCHET, Teresa. Partidos políticos e sub-representação feminina: um estudo sobre recrutamento legislativo e financiamento de campanhas no Brasil. In: PAIVA, Denise (Org.). Mulheres, política e poder. Goiânia: Cânone Editorial, 2011. p. 161-188.

SACCHET, Teresa; SPECK, Bruno W. Financiamento eleitoral, representação política e gênero: uma análise das eleiçóes de 2006. Opiniáo Pública, v. 18, n. 1, p. 177-197, 2012.

SAMPAIO, Rafael et al. A construção do campo de Internet \& Política: análise dos artigos brasileiros apresentados entre 2000 e 2014. In: SILVA, Sivaldo et al. (Orgs.). Democracia digital, comunicação 
política e redes: teoria e prática. Rio de Janeiro: Folio Digital/Letra e Imagem, 2016. p. 77-110.

SANTOS, Fabiano; PAULA, Carolina Almeida de; SEABRA, Joana. Cotas e movimentos sociais nas estratégias partidárias de inserção de mulheres na vida parlamentar: os casos do Rio de Janeiro e Ceará nas eleiçóes de 2010 para a Câmara dos Deputados. In: ALVES, José Eustáquio D.; PINTO, Céli Regina J.; JORDÃO, Fátima (Orgs.). Mulheres nas eleiçóes 2010. São Paulo: ABCP/Secretaria de Políticas para as Mulheres, 2012. p. 315-336.

SCHWEITZER, Eva. Innovation or Normalization in E-Campaigning? A Longitudinal Content and Structural Analysis of German Party Websites in the 2002 and 2005 National Elections. European Journal of Communication, v. 23, n. 4, p. 449-470, 2008.

SILVA, Sivaldo et al. Concepçóes, debates e desafios da democracia digital. In: SILVA, Sivaldo et al. (Orgs.). Democracia digital, comunicaçáo política e redes: teoria e prática. Rio de Janeiro: Folio Digital/Letra e Imagem, 2016. p. 17-38.

Texto recebido em 28 de outubro de 2020. Aprovado em 27 de novembro de 2020. 